\title{
TRIENINE, AN ANTITUMOR TRIENE ANTIBIOTIC
}

\author{
Adorjan Aszalos, Robert S. Robison, \\ Paul Lemanski and Bernard Berk \\ The Squibb Institute for Medical Research \\ New Brunswick, New Jersey, U.S.A. \\ (Received for publication September 7, 1968)
}

\begin{abstract}
Trienine, a new antitumor antibiotic, was isolated from the fermentation broth of Streptomyces SC 3725. The substance, which contains three conjugated double bonds in a molecule weighing approximately 1,400 , is active in vitro against gram-positive bacteria, as well as against several yeast and fungi. Trienine is also active as an inhibitor of the growth of the $5 \mathrm{WM}$ tumor.
\end{abstract}

During a search for antitumor antibiotics among the actinomycetes, a triene antitumor antibiotic was isolated from the culture broth of Streptomyces SC3725. Although many antibiotics with conjugated double bonds are described in the literature, only two triene antibiotics are known ${ }^{1,2)}$.

In the present communication, we wish to report the fermentation, isolation, and determination of the properties of a third triene antibiotic, with a molecular weight of about 1,400 .

\section{Fermentation}

Streptomyces SC3725 was isolated by conventional plating techniques from a soil sample obtained at Piscataway, New Jersey. It is maintained on an agar slant made with 2 medium containing from $20 \mathrm{~g}$ of tomato paste, $20 \mathrm{~g}$ of oatmeal, and $500 \mathrm{ml}$ of boiling water. The medium is cooled to a thin gruel, filtered, added to $15 \mathrm{~g}$ of agar in $500 \mathrm{ml}$ of water, and sterilized at $121^{\circ} \mathrm{C}$ for 20 minutes. On this medium, the aerial mycelium is gray colored and a light brown soluble pigment diffuses into the agar.

A portion of the growth from a well-sporulated slant is suspended in $0.01 \%$ Duponal solution and used to inoculate $50 \mathrm{ml}$ of sterilized broth in a $250-\mathrm{ml}$ flask. The broth has the following composition:

$\begin{array}{lrlr}\text { Soybean meal } & 15 \mathrm{~g} & \left(\mathrm{NH}_{4}\right)_{2} \mathrm{SO}_{4} & 5 \mathrm{~g} \\ \text { Glucose } & 55 \mathrm{~g} & \mathrm{~K}_{2} \mathrm{HPO}_{4} & 1 \mathrm{~g} \\ \mathrm{CaCO}_{3} & 7 \mathrm{~g} & \text { Corn steep liquor } & 2.5 \mathrm{~g} \\ \mathrm{KH}_{2} \mathrm{PO}_{4} & 1 \mathrm{~g} & \text { Distilled water } & 908.5 \mathrm{~g}\end{array}$

After 48 hours incubation at $25^{\circ} \mathrm{C}$ on a rotary shaker, the contents of the flask are transferred to $1,000 \mathrm{ml}$ of the sterile broth in a $4,000-\mathrm{ml}$ flask and again incubated for 48 hours. The entire contents of the flask are used then to inoculate a 380-liter germinator tank containing 225 liters of broth with $0.01 \%$ defoamer (UCON Lubricant). Growth continues for 48 hours at $25^{\circ} \mathrm{C}$, with a superficial air velocity of $30.5 \mathrm{~cm} / \mathrm{min}$. (1.0 ft/min.) and agitation equivalent to $0.2 \mathrm{HP} / 360$ liters.

Approximately 55 liters of the germinator contents are used to inoculate 500 liters 
of the medium in a 760-liter fermentor. Fermentation is conducted for 120 hours at $25^{\circ} \mathrm{C}$, with superficial air velocity of $30.5 \mathrm{~cm} / \mathrm{min}$. $(1.0 \mathrm{ft} / \mathrm{min}$.) and agitation equivalent to $0.2 \mathrm{HP} / 360$ liters.

\section{Isolation}

After 120 hours of fermentation, the whole broth is filtered, after the addition of filter aid. Since most of the antibiotic is in the filter cake, the filtrate is discarded. The wet filter cake is extracted twice with one liter isopropanol (IPA) per $\mathrm{kg}$ of cake. The combined IPA extracts are concentrated in vacuo to $1 / 60$ of the original volume. To this concentrate, which is an aqueous suspension, four volumes of IPA are added and the suspension is kept at $5^{\circ} \mathrm{C}$ for $4 \sim 6$ hours. The resulting precipitate is filtered off and dried in vacuo at $30^{\circ} \mathrm{C}$. Yield is $250 \sim 300 \mathrm{~g}$ brown powder from 500 liters of broth.

Further purification of the crude product is achieved by solvent extraction, countercurrent distribution, and reprecipitation. The procedure is as follows:

Ten grams of crude antibiotic are dissolved in 1 liter $n$-butanol, saturated with water, and one liter water, saturated with $n$-butanol, and the $\mathrm{pH}$ is adjusted to 2.5 with dilute HCl. The water phase is removed and the $n$-butanol phase is shaken with one liter water, saturated with $n$-butanol. The water phase is removed again and the extraction process is repeated three more times. The $\mathrm{pH}$ is kept at 2.5 throughout. After removal of the last water phase, the $n$-butanol solution is neutralized with dilute $\mathrm{NaOH}$ and taken to dryness. The yield is about two g. Materials extracted into the water phase have negligible amounts of in vivo activity and are discarded.

The extracted material $(2 \mathrm{~g})$ is dissolved in a mixture of $125 \mathrm{ml} n$-butanol, saturated with water, and $125 \mathrm{ml}$ water, saturated with $n$-butanol, and the $\mathrm{pH}$ is adjusted to 10 with dilute $\mathrm{NaOH}$. A five-step countercurrent distribution process is carried out at $\mathrm{pH} 10$ in separator funnels over a period of $4 \sim 6$ hours.

After the countercurrent process, the contents of all funnels are neutralized with dilute $\mathrm{HCl}$ and taken to dryness. The solids are then tested in the $5 \mathrm{WM}$ tumor system $^{3)}$.

The fractions $\$ 2$ and $\geqslant 3$ ) that have the highest activity in vivo are further purified by reprecipitation. The combined yield of these fractions is $0.4 \mathrm{~g}$. Both fractions showed the same activity in vivo in the $5 \mathrm{WM}$ system.

$\begin{array}{lcccl}\text { Dose }(\mathrm{mg} / \mathrm{kg} / \mathrm{day}) & 50 & 25 & 12 & 6 \\ \mathrm{~T} / \mathrm{C} & \text { tox. } & 0.09 & 0.22 & 0.41\end{array}$

In the reprecipitation process, $2 \mathrm{~g}$ of active material of this description are extracted twice with $60 \mathrm{ml}$ pyridine-water $(5: 1)$. The insoluble residue is discarded and the solution is concentrated to about $10 \mathrm{ml}$. To this concentrate, four volumes of IPA are added. The precipitate formed is washed with IPA and dried in vacuo at $35^{\circ} \mathrm{C}$. This reprecipitation process is repeated until there is no change in ultraviolet absorption. Usually two or three reprecipitations are sufficient. The product is an amorphous off-white material (yield is $0.2 \mathrm{~g}$ ). 


\section{Chemical and Physico-chemical Properties}

Trienine is an amorphous light-yellow powder that melts at $163 \sim 165^{\circ} \mathrm{C}$ and decomposes at $180^{\circ} \mathrm{C}$. It is soluble in methanol, pyridine, and dimethylformamide (DMF) and sparingly soluble in water, but insoluble in most other organic solvents.

Trienine gives a positive Tollens ${ }^{4}$ and a negative FenLING ${ }^{5)}$ reaction. The ninhydrin reaction is positive only after acid hydrolysis. In the acid hydrolysate, no amino acids could be detected by paper chromatographic methods. Elemental analysis of preparations obtained at two different times gave the following values: C $55.00 \sim 54.49$, H $7.85 \sim 8.13, \quad N \quad$ I.34 $0.99 \%$. No sulfur or halogen can be detected in trienine preparations. Nonaqueous titrations for acidic function, with potassium methylate, gave an equivalent weight of 1,500 and for basic function, with perchloric acid, gave an equivalent weight of 1,380 .

Measurements with the analytical

Fig. 1. Ultraviolet spectrum of trienine

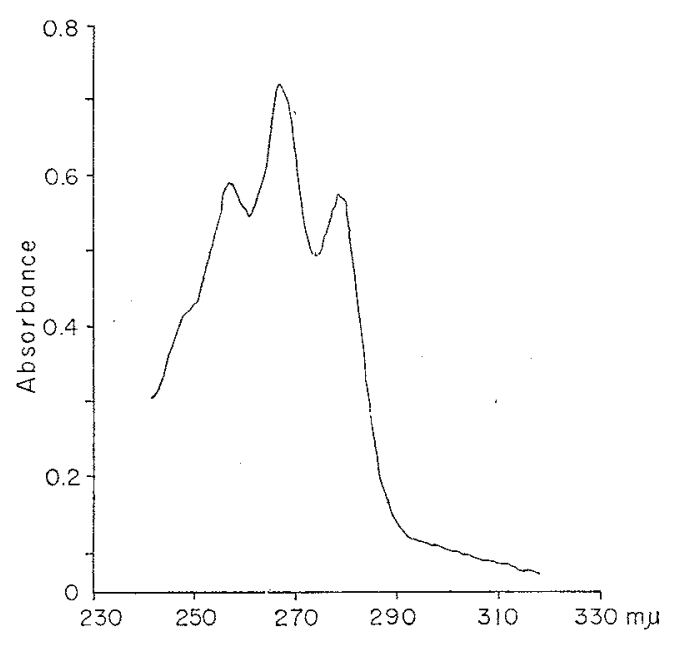

Fig. 2. Infrared spectrum of trienine

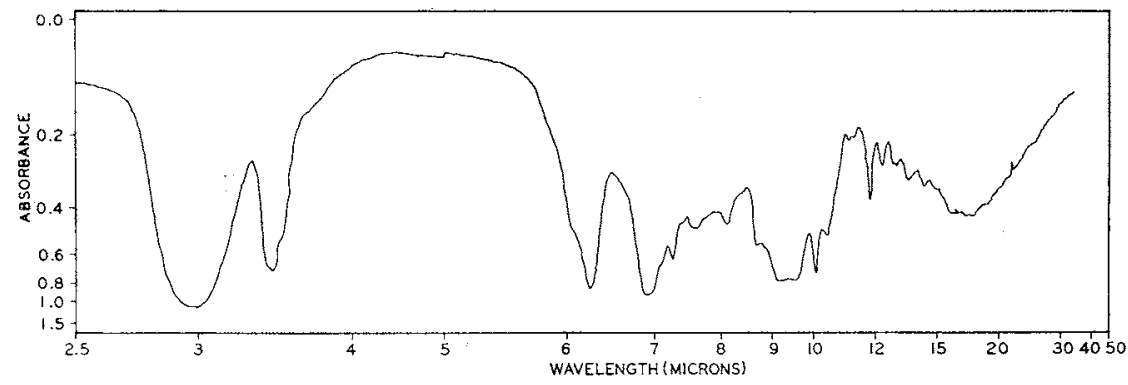

ultracentrifuge were carried out according to methods described by KIRSCHBAUM and Aszalos ${ }^{6}$, using the ARCHIBALD approach to sedimentation equilibrium at $42,000 \mathrm{rpm}$ and $75^{\circ}$ Schlieren phase bar angle at $20^{\circ} \mathrm{C}$. In phosphate buffer, two components

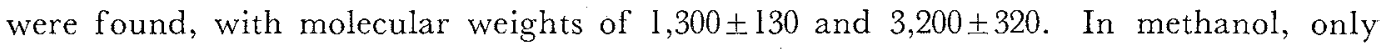
one component was found, with moelcular weight of $1,430 \pm 140$. The component with molecular weight of 3,200 is believed to be a dimer.

The ultraviolet spectrum of trienine in methanol (Fig. 1) shows absorption typical for a triene. The maxima are located at 257, 267, and $278 \mathrm{~m} \mu$ with $\mathrm{E}_{1 \mathrm{~cm}}^{1 \%}$ of 332,390 , and 322 , respectively.

As calculated from the $\lambda_{\max }$ at $267 \mathrm{~m} \mu$ of $2,4,6$-octratriene ${ }^{7,8)}$ and from the $\mathrm{E}_{1 \mathrm{~cm}}^{1 \%}$ at $267 \mathrm{~m} \mu$ of trienine, the equivalent weight of trienine is 1,360 . Trienine loses its ultraviolet characteristics upon standing in methanolic solution exposed to light. 
The infrared spectrum of trienine $(\mathrm{KBr})$ shows absorption at 3.0 , $3.42,6.29,6.90,7.25,8.12,8.70,10.07$, and $11.80 \mu$, as shown in Fig. 2 . (The IR spectra of three separate trienine preparations were superimposable). It is postulated that trienine contains ionized carboxyl and hydroxyl groups. Absorption at $10.07 \mu$ is due to the triene group $p^{1)}$. The characteristic absorption around $5.8 \mu$, attributable to the lactone group in other polyenic antibiotics, is not present.

Trienine moves as a single spot in paper chromatographic systems. In the solvent system $\mathrm{BuOH}-\mathrm{AcOH}-\mathrm{H}_{2} \mathrm{O}(4: 1: 5)$, trienine has an $\mathrm{Rf}$ of 0.55 and, in the solvent system $5 \%$ DMF in $\mathrm{MeOH}$, an $\mathrm{Rf}$ of 0.7 .

Attempts to determine the purity of the trienine preparations by means of CRAIG countercurrent distribution failed; all in vivo biological activity disappeared. Loss of activity may have been due to exposure of trienine to light for the long periods required for disappearance of the emulsions formed by this compound in three different solvent systems tried.

\section{Biological Properties}

Trienine is weakly active against microorganisms in vitro. The antimicrobiological spectrum is given in Table 1. Trienine is also active against the $5 \mathrm{WM}$ tumor system; activity against this tumor system in vivo is as follows (Hazleton Laboratories, Inc., Falls Church, Virginia):

$$
\begin{array}{lclll}
\text { Dose }(\mathrm{mg} / \mathrm{kg} / \text { day }) & 4 & 2 & 1 & 0.5 \\
\mathrm{~T} / \mathrm{C} & \text { tox. } & 0.16 & 0.53 & 0.72
\end{array}
$$

The loss in ultraviolet absorption in methanolic solution - as mentioned above-is accompanied by a loss in biological activity. In the dry form, at room temperature, trienine is stable for at least four months.

\section{Acknowledgement}

The authors are grateful to Dr. Joel Kinschbaum (The Squibb Institute, Analytical Research Department) for the ultracentrifuge measurements and to Joseph Alicino and Joseph Hydro (The Squibb Institute, Analytical Research Department) for the microanalyses. We also thank HAROsD BASCH (The Squibb Institute, Microbiological Department) for the microbiological data.

We wish to thank Helen Koury and Gloria Jennings for excellent technical assistance.

We are indebted to Dr. David Frost (The Squibb Institute, Biological and Chemical Research Division) for preparing this manuscript for publication.

This work was carried out as part of the effort on Cancer Chemotherapy National Service Center Contract PH 43-65-1056. 


\section{References}

1) Coronelit, C.; R. C. Pasqualucci, J. E. Thiemann \& G. Tamoni: Mycotrienin, a new polyene antibiotic isolated from Streptomyces. J. Antibiotics, Ser. A $20: 329 \sim 333,1967$

2) Armstrong, J. J.; J. F. Grove, W. B. Turner \& G. Ward: An antifungal triene from a Streptomyces sp. Nature $206: 399 \sim 400,1965$

3) C.C.N.S.C. Protocols for screening chemical agents and natural products against animal tumors and other biological systems. Walker 256 (5 WM). Cancer Chemoth. Reports $25: 12,1962$

4) Fieser, L. F.: Experiments in organic chemistry. p. 114, D. C. Heath \& Co., Boston, 1955

5) FieSer, L. F.: Experiments in organic chemistry. p. 112. D. C. Heath \& Co., Boston, 1955

6) Kirschbaum, J. \& A. Aszalos: Molecular weight of the antifungal antibiotic saramycetin. J. Pharm. Sci. $56: 410 \sim 411,1967$

7) WALKeR, R. D., Jr. \& J. E. HAwKINS: The ultraviolet absorption spectra of some terpene hydrocarbons. J. Am. Chem. Soc. 74: 4209 4210, 1952

8) O'Connor, R. T. \& L. A. Goldbeatt: Correlation of ultraviolet and infrared spectra of terpene hydrocarbons. Anal. Chem. $26: 1726 \sim 1737,1954$ 